DETECTION OF ENTEROVIRUSES BY ONA-RNA DOT HYBRIDIZATION--PR OGRESS TOWARD A RAPID DIAG1134. N OSIS. Harley A. Rotbart, Myron J. Levin, Luis P. Center, Depts. of Pediatrics and Microbiology, Denver.

The antigenic heterogeneity among the more than 70 serotypes of enteroviruses has been the major obstacle to rapid diagnosis of infections due to these agents. A common antigen detectable by immunodiagnostic techniques has not been found. The enteroviruses do, however, share numerous physico-chemical and microbiological characteristics, suggesting some genetic conservation may exist across
all of the subgroups. To test that hypothesis, we radioactively labeled all of the subgroups. To test that hypothesis, we radioactively labeled fragments of DNA which are complementary ( $C D N A)$ to the genomic
RNA of type 1 poliovirus. These CDNA sequences have been cloned RNA of type 1 poliovirus. These CDNA sequences have been cloned
into the $P B R 325$ plasmid of E. coli HB101. We then infected separate plates of LLC-MK2 tissue culture cells with type 1, type 2, and type 3 polioviruses, coxsackieviruses $A 9$ and $B 1$ and echovirus 11-representative members of the major enteroviral subgroups. Using standard techniques for dot hybridization, our type 1 poliovirusderived molecular probes successfully detected all viruses tested. This hybridization technique is sensitive enough to follow the time course of viral replication in tissue culture. Pre-treatment of LLCcourse of viral replication in tissue culture. Pre-treatment of $L L C-$ hybridization, reflecting the anti-viral effect of this drug. Finally, preliminary trials of cerebrospinal fluid from patients with aseptic meningitis suggest that our molecular probes may be useful in clinical setting for the rapid diagnosis of enteroviral infections.

\section{$\dagger 1135$} ROLE OF INTRAVASCULAR REPLICATION IN THE PATHOGENEBACTEREMIA. Lorry G. Rubin, Andre Zwahlen, E. xon. SuNY at stony Brook \& Children's Hospital of Long Island Jewish-Hillside Medical Center, Dept. of Med., New Hyde Park, NY \& Johns Hopkins U., Dept. of Peds. Baltimore, MD. The occurrence of sustained bacteremia is a critical determinant in the pathogenesis of experimental Hib meningitis. We studied the potential role of (1) extravascular and (2) intravascular replication of $\mathrm{Hib}$ in the initiation of bacteremia. To identify tissues, in addition to nasopharynx (np), where Hib might replicate prior to seeding the bloodstream, rats (age 20 d.) were sacrificed 6-24 h. after intranasal (i.n.) inoculation with $10^{5} \mathrm{Hib}$ and whole organs (liver, spleen, etc.) and body fluids (CSF, joint fluid, etc.) were cultured to recover Hib. We were unable to recovex Hib from any putative extravascular We were unable to recovex Hib from any putative extravascular To evaluate the potential contribution of intravascular replication in infiation of Hib bacteremia, rats were injected i.v. with a small inoculum (<100 $\mathrm{Hib}$ ). Serial blood cultures showed a prompt (negligible $\mathrm{lag}$ ) and exponential increase in bacterial counts in the blood in the ensuing $6 \mathrm{~h}$. (mean doubling time $\sim 47$ min.). We noted a similar exponential increase in bacterial counts when serial blood cultures were performed 12-18 h. after intranasal inoculation with Hib. Thus, a few surviving Hib that enter the bloodstream from the np may undergo intravascular replication to initiate a sustained, high level $\left(210^{3}\right.$ Hib per $\left.\mathrm{mI}\right)$ bacteremia.

a 1136 (CRP) IN THE EVOLUTION OF BACTERIAL INFECTION OF Bienvenu, and Alistair G.S. Philip, Depts, of Pediatrics, Hôpital Debrousse, Lyon, France and Maine Medical Center, Portland,Maine. AGP (orosomucoid) and CRP provide help in the diagnosis of bacterial infection in neonates. Their use in following the course of systemic neonatal infection was evaluated in 49 neonates (GA:mean35 weeks, range 26-41w;BW:mean2206g., range 880-4400) using sequential, quantitative (nephelometric) determinations. Early infection ( $<6$ days of age) was observed in 28 patients: 1ate in 21 patients. The outcome was favorable in all but 8 infants. Initial AGP and CRP concentrations were (mean $\pm 1 \mathrm{SD}$ ) $133 \pm 75 \mathrm{mg} / \mathrm{dl}$ and $8.4 \stackrel{i}{ \pm} 7.5 \mathrm{mg} / \mathrm{dl}$. After $5-6$ days of favorable evolution, CRP decreased to a mean of $4.7 \mathrm{mg} / \mathrm{dl}(<0.5-17.5)$ and after $13-16$ days to $2.0 \mathrm{mg} / \mathrm{dl}(<0.5-18.8)$. Serum AGP increased to $142 \pm 73$ $\mathrm{mg} / \mathrm{dl}$ and then decreased to $116 \pm 75 \mathrm{mg} / \mathrm{dl}$ after the same time intervals. Higher values were associated with meningitis. During the $3 \mathrm{rd}$ week, no CRP value was above $0.8 \mathrm{mg} / \mathrm{dl}$, and AGP was normal at $86+40 \mathrm{mg} / \mathrm{dl}$. The normalization of serum AGP was similar to clinical healing. In contrast, a dramatic increase of CRP was observed in patients with a bad outcome, especially 3 patients who died and two with profound neurologic damage. In one patient with arthrit with a re-elevation of serum AGP while serum C.RP was normal. neonates with bacterial infection. They suggest that CRP is a reflection of the efficacy of the treatment and that the normallization of serum AGP coincides with recovery.
COMPARISON OF NATIVE AND REDUCED AND ALKYLATED HUMAN $\$ 1137$ IV IMMUNE SERUM GLOBULIN (ISG) IN EXPERIMENTAL H. IN and G. Siber. (Spon. K. MCIntosh). Children's Hospital and DanaFarber Cancer Inst., Dept. Inf. Dis., Boston, MA. Reduced and alkylated (RA) ISG for intravenous use contains IgG with disrupted inter-heavy chain disulfide bonds. This change alters FC function, particularly the ability to fix complement. We compared protective activity of RA and native (N) ISG's in infant rats passively immunized with ISG and then challenged with $10^{3} \mathrm{Hib}$ ip. Both ISG's contained 20,000 ng anti$\mathrm{PRP} \mathrm{Ab} / \mathrm{ml}$ and were cidal in vitro in the presence of complement. Cidality was blocked by absorption with PRP. Cumulative bacteremia, meningitis and death 5 days after challenge were:

\begin{tabular}{|c|c|c|c|c|c|c|c|}
\hline \multirow{3}{*}{$\begin{array}{l}\text { PRP Ab dose (ng) } \\
\text { Bacteremia ( } 8 \text { ) }\end{array}$} & \multirow{2}{*}{\multicolumn{2}{|c|}{$\frac{N}{3,000} \frac{R A}{-}$}} & \multirow{2}{*}{\multicolumn{2}{|c|}{$\frac{\mathrm{N}}{1,50 \frac{\mathrm{RA}}{0}}$}} & \multirow{2}{*}{\multicolumn{2}{|c|}{$\underline{N}_{375} \stackrel{\text { RA }}{=}$}} & \multirow{2}{*}{$\frac{\text { Saline }}{0}$} \\
\hline & & & & & & & \\
\hline & 0 & 17 & 0 & 40 & 100 & 100 & 100 \\
\hline Meningitis ( 8 ) & 0 & 0 & 0 & 40 & 33 & 100 & 100 \\
\hline Death $(8)$ & 0 & 0 & 0 & 20 & 0 & 50 & 73 \\
\hline D1 serum [PRP $A b]$ & 771 & 804 & 395 & 513 & 160 & 130 & $<50$ \\
\hline
\end{tabular}
$\begin{array}{llllllll}\text { D1 serum [PRP Ab] } & 771 & 804 & 395 & 513 & 160 & 130 & <50\end{array}$ $\begin{array}{lccccccc}X \mathrm{cfu} \times 10^{3} / \mathrm{ml} & 0 & 0.1 & 0 & 5.4 & 2.2^{*} & 40^{*} & 360 \\ \text { High doses of both preparations of anti-PRP Ab were protective. }\end{array}$ At lower doses, bacteremia, meningitis and mortality rates as well as the magnitude of bacteremia $(p=.025)$ * were higher in rats treated with RA ISG than N ISG. We conclude that RA ISG was less efficacious than N ISG in protecting infant rats from Hib infection. The mechanism of this difference may be related to altered FC effector function of RA ISG. Differences in pro-
tective Ab specificities other than anti-PRP, however, cannot
be excluded.

\section{$\dagger 1138$} ALTERED HELPER:SUPPRESSOR LYMPHOCYTE RATIO DURING

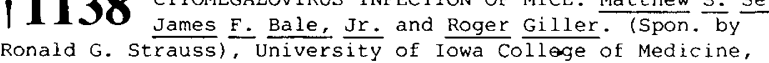
Department of Pediatrics, lowa City.

Cytomegalovirus (CMV) infections of humans and experimental animals have been associated with altered cell mediated immunity. In a murine model, we have observed an increased susceptibility to secondary infection during acute murine CMV (MCMV) infection. To further investigate the effect of MCMV infection upon host defense, we studied helper:suppressor lymphocyte (H:S) ratios in Balb/c mice undergoing sublethal MCMV infection. On days $1,3,5$ and possibly $9, \mathrm{H}: \mathrm{S}$ ratios were reduced. On day 3 the $H: S$ ratio was 0.82 in MCMV-infected mice vs 1.78 in controls $(p<0.01)$ and on day $5,0.59$ vs $3.85(p<0.01)$. On days 3 and 5 . reduced H:S ratios were attributable to decreased absolute numbers of helper lymphocytes. Thereafter, suppressor cell numbers increased. Infectious MCMV was recovered from blood lymphocytes and bone marrow on days 3,5 and 9 and from spleen on days 1 through 16 . Alterations in $\mathrm{H}: \mathrm{S}$ ratio appeared to correlate most closely with recovery of infectious virus trom spleen $(p=0.07)$. Examination of bone marrow preparations suggested diminished cellularity on days 1 through 5 . These results indicate that acute MCMV infection is associated with reduced $H: S$ ratios and suggest that altered $\mathrm{H}: \mathrm{S}$ ratios may correlate with enhanced susceptibility to secondary infection. These observations may be relevant to the association between CMV and opportunistic infections in human organ transplant recipients as well as in patients with the acquired immune deficiency syndrome.

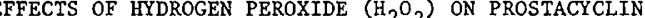
1139 AND OTHER VASCULAR ARACHIDONIC ACID METABOLITES. B.N.Y. Stuart, Dept Pediatrics, SUNY, Upstate Med Ctr, Syracuse, N.Y.

Local production of $\mathrm{H}_{2} \mathrm{O}_{2}$ by granulocytes during phagocytosis affects the function of red cells and platelets. We evaluated the effects of $\mathrm{H}_{2} \mathrm{O}_{2}$ on vascular arachidonic acid (AA) metabolism and report that $\mathrm{H}_{2} \mathrm{O}_{2}$ treatment inhlbits prostacyclin ( $\mathrm{PGI}_{2}$ ), $\mathrm{PGE}_{2}$ and PGF $\alpha$ production. Short term exposure of human umbilical arteries $\mathrm{H}_{0}^{\alpha} \mathrm{H}_{2} \mathrm{O}_{2}$ (25 to $200 \mathrm{\mu m}$ ) resulted in a concentration dependent inhibition in the ability of vessels to produce $6 \mathrm{KPGF}$ (the ent Inhibition in the ability of vessels to produce $6 \mathrm{KPGF}{ }_{1} \alpha$ (the stable metabolite of PGI ${ }_{2}$ ) elther from endogenous or exogenously
provided substrate. Following exposure to $200 \mu \mathrm{M} \mathrm{H} \mathrm{H}_{2} \mathrm{O}_{2}$, vessels provided substrate. Following exposure to $200 \mu \mathrm{M} \mathrm{H} \mathrm{H}_{2} \mathrm{O}_{2}$; vessels
produced $1.45+0.24$ (1SE) pmol 6KPGF per mg (by $\mathrm{KIA}$ compared produced $1.45 \pm 0.24$ (1SE) pmol $6 \mathrm{KPGF}$ per mg (by KIA) compared
to $2.08+0.29$ in paired control segments, an inhibition of $33 \%$ $(n=8 ; p<0.001)$. Mean Inhibitions of $15 \%$ and $21 \%$ were observed at $\mathrm{H}_{2} \mathrm{O}_{2}$ concentrations of 50 and $100 \mu \mathrm{M}$. Inhibition was present Production of $6 \mathrm{KPGF}_{1} \alpha, \mathrm{PGE}_{2}$ and $\mathrm{F}_{2 \alpha}$ from exogenously provided ${ }_{14} \mathrm{C}$ AA was inhibited to a similar degree in microsomes from these vessels, suggesting that the effect occurred at the cyclo-oxygenase level. Following incubation with $200 \mathrm{\mu M} \mathrm{H} \mathrm{H}_{2} \mathrm{O}_{2}$, mean ${ }^{4} \mathrm{C}$ metabolite production was $449+134$ pmol per mg microsomal protein compared to palred control values of $612 \pm 146$ pmol, $(n=5 ; p<0.01)$. Catalase $(250 \mathrm{U} / \mathrm{m} 1)$ abolished the effect, whereas SOD $(2.5 \mathrm{\mu g} / \mathrm{m} 1)$ did not. PGI, $\mathrm{PGE}_{2}$ and $\mathrm{F}_{2}$ have been shown to affect leucocyte adherance to vascular endothelium, and to play a role in edema formation. Release of $\mathrm{H}_{2} \mathrm{O}_{2}$ from phagocytes may play a role $1 \mathrm{n}$ 